\title{
Silicon-depth profiling with Rutherford backscattering in photoresist layers; a study on the effects of degradation
}

\section{Citation for published version (APA):}

IJzendoorn, van, L. J., \& Schellekens, J. P. W. (1989). Silicon-depth profiling with Rutherford backscattering in photoresist layers; a study on the effects of degradation. Journal of Applied Physics, 65(2), 799-804.

https://doi.org/10.1063/1.343069

DOI:

10.1063/1.343069

Document status and date:

Published: 01/01/1989

\section{Document Version:}

Publisher's PDF, also known as Version of Record (includes final page, issue and volume numbers)

\section{Please check the document version of this publication:}

- A submitted manuscript is the version of the article upon submission and before peer-review. There can be important differences between the submitted version and the official published version of record. People interested in the research are advised to contact the author for the final version of the publication, or visit the $\mathrm{DOI}$ to the publisher's website.

- The final author version and the galley proof are versions of the publication after peer review.

- The final published version features the final layout of the paper including the volume, issue and page numbers.

Link to publication

\section{General rights}

Copyright and moral rights for the publications made accessible in the public portal are retained by the authors and/or other copyright owners and it is a condition of accessing publications that users recognise and abide by the legal requirements associated with these rights.

- Users may download and print one copy of any publication from the public portal for the purpose of private study or research.

- You may not further distribute the material or use it for any profit-making activity or commercial gain

- You may freely distribute the URL identifying the publication in the public portal.

If the publication is distributed under the terms of Article 25fa of the Dutch Copyright Act, indicated by the "Taverne" license above, please follow below link for the End User Agreement:

www.tue.nl/taverne

Take down policy

If you believe that this document breaches copyright please contact us at:

openaccess@tue.nl

providing details and we will investigate your claim. 


\title{
Si-depth profiling with Rutherford backscattering in photoresist layers; a study on the effects of degradation
}

\author{
L. J. van IJzendoorn and J.P. W. Schellekens \\ Philips Research Laboratories, P. O. Box 80000 , 5600 JA Eindhoven. The Netherlands
}

(Received 16 May 1988; accepted for publication 23 August 1988)

\begin{abstract}
The reaction of a silicon-containing vapor with a photoresist layer, as used in some dry developable lithographic processes, was studied with Rutherford backscattering spectrometry. Degradation of the polymer layer under ion beam irradiation was observed, but it was found that this had no infuence on the shape of the Si-depth profile and the total areal density. The RBS measurements were also verified with secondary ion mass spectrometry measurements. To describe the degradation process that occurs in polymeric layers upon ion beam exposure, elastic recoil detection measurements were carried out on polystyrene layers. Only one doseindependent cross section for carbon and only one for hydrogen were needed to describe the degradation behavior.
\end{abstract}

\section{MTRODUCTION}

Dry development of photoresist patterns with an oxygen plasma is becoming a very interesting option for submicron hithography. The miniaturization of integrated circuits has pushed conventional, wet developable, photoresist systems to the edge of their potentials. The main advantage of dry development lies in the fact that with a proper tuning of the plasma etch parameters giving highy anisotropic etching, relief images with vertical sidewalls can be obtained, even over nonplanar reflective substrates. An elegant dry developable resist system was recently proposed by Coopmans and Roland. ${ }^{2}$ The principle of this so-called DESIRE process is shown in Fig. 1.

Selective etch resistance of the organic resist material towards an oxygen plasma is accomplished by selective in- corporation of silicon into the photoresist. The sample is placed on the lower electrode of a reactive ion etcher which is capacitively coupled to an rield (13.56 MHz). The upper electrode is grouncied and therefore in this configuration positive ions $\left(\mathrm{O}_{2}{ }^{-}\right)$will be drawn out of the plasma onto the lower electrode. Due to this ion bombardment, the etch rate in the vertical direction can become much higher than the lateral etch rate. Organic resist material containing a suffcient amount of silicon will be protected from the etcining species due to the formation of a protective silicon dioxide skin. In this way a relief image with vertical sidewals can be obtained.

The selective incorporation of silicon into the resist layer is achieved by treating this polymer layer, after a patternwise UV exposure, with a silicon-containing gas such as hexamethyldisilazane (HMDS). The mechanism of the reaction of silicon-containing gases with polymeric resist layers was extensively studied by Visser et al. In that study the reaction of HMDS with photoresists based on polyvinylphenol or novolac was investigated. The chemical reaction was followed using Fourier transform infrared spectroscopy (FT-IR). The conversion of the phenolic hydroxyl groups was determined by probing the intensity of the Si-O-aryl stretching vibration. The conversion can also be obtained by gravimetry or layer thickness measurements. However, all these techniques only provide bulk information on the amount of silicon incorporated.

To obtain a profile of the silicon concentration as a function of depth in these resists, the possibility of using Rutherford backscattering spectrometry (RBS) was investigated. Recently, Mills, Palmstrom, and Kramer already demonstrated the power of RBS on organic compounds with a study on the difusion of trichloroethane (TCE) in PMMA, while elastic recoil detection (ERD) has also been used to obtain concentration profiles of undeuterated polystyrene in a deuterated matrix. ${ }^{5}$ The application of ion beam analysis to organic compounds, however, is seriously limited by degradation under megaelectron volt irradiation. In contrast to semiconductor materials and metals the entire character of the polymer can be altered. Hllustrative examples are provided by Venkatesan and co-workers ${ }^{6}$ who studied the ionbeam-induced conductivity of PVC, PMMA, and several other compounds. A closer look with mass spectrometry revealed the out-diffusion of small molecules such as $\mathrm{H}_{2}, \mathrm{CH}_{4}$, $\mathrm{CO}_{2}$, and $\mathrm{CH}_{3} \mathrm{OH}$ from PMMA upon $2 \mathrm{MeV} \mathrm{He}{ }^{+}$irradia-

a)

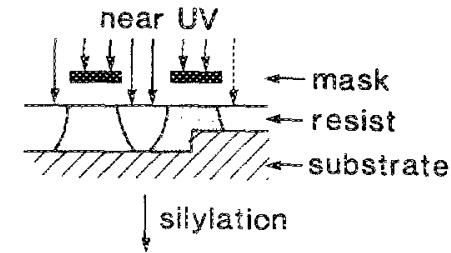

b)

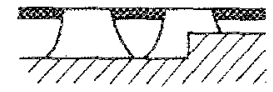

FIG. 1. The DESIRE process.

$$
\mathrm{O}_{2} \mid-\mathrm{RIE}
$$

c)

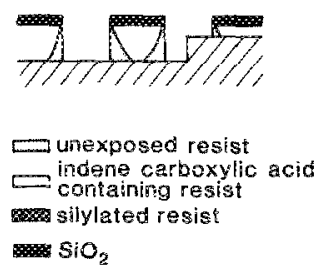


tion. ${ }^{7,8}$ These degradation effects throw serious doubts on the versatility of RBS with regard to these materiais. Further investigations of Green and Doyle, ${ }^{5}$ who compared diffusion coefficients obtained in a number of ERD experiments with different incident ions, showed absolute values for $D$ varying by as much as a factor of 1.6. The differences were at ributed to degradation effects and could be qualitatively explained by means of a model describing this breakdown of the resist.

Obviously caution is required in interpreting the $R B S$ data on silylated resist layers. The shape of the Si profiles, as well as the number of Si atoms incorporated, might change as a function of dose. This consideration led to the series of 2 $\mathrm{MeV} \mathrm{He}^{+} \mathrm{RBS}$ and ERD experiments described in this paper, in which beam current as well as total integrated dose were varied.

Secondary ion mass spectrometry (SIMS) has been used to verify the RBS results and to measure the effect of degradation on the Si profile. In addition, an understanding of the degradation effects was gained by measurements on polystyrene as a model system. The decrease in the hydrogen count rate in ERD experiments and the shift of the Si substrate edge in corresponding $\mathrm{RBS}$ spectra have been used to develop a model description.

\section{EXPERIMEN}

\section{A. Sample preparation}

In our study we used the UCB-Plasmask photoresist which was spin coated on 3 -in. silicon wafers at 5000 rpm for $30 \mathrm{~s}$ and prebaked at $90^{\circ} \mathrm{C}$ for $30 \mathrm{~min}$, resulting in a layer thickness of $1.70 \mu \mathrm{m}$.

UV exposures were carried out with a Philips super pressure mercury source (HPA-400). The coated wafer was then placed in a small glass reaction vessel which was heated with a heating block. The temperature at which the silylation reaction was carried out was measured with a thermocouple directly on the wafer. The reaction vessel could be evacuated and once the desired temperature was reached, the silylating agent hexamethyldisilazane (HMDS, Janssen Chimica) was injected with a syringe through a septum.

All etch experiments were done in a modified Balzers sputter system. The upper electrode was grounded, the lower, quartz, electrode was connected through a blocking capacitor with an rf field (13.56 MHz). The experiments were carried out with a power density of approximately $0.22 \mathrm{~W} /$ $\mathrm{cm}^{-2}$, a pressure of $0.7 \mathrm{~Pa}$, and an oxygen flow of $15.1 \mathrm{sccm}$. The polystyrene samples used in the ERD experiments were coated from a solution of $1 \mathrm{~g}$ polystyrene in $18 \mathrm{~g}$ of $x y$ lene at $5000 \mathrm{rpm}$ for $30 \mathrm{~s}$ and prebaked at $100^{\circ} \mathrm{C}$ for $30 \mathrm{~min}$, result ing in a layer thickness of $0.56 \mu \mathrm{m}$.

\section{B. RBS and ERD experiments}

RBS and ERD experiments were performed with 2000 $\mathrm{keVHe}^{+}$ions produced by a $2.5 \mathrm{MV}$ Van de Graafi accelerator. RBS analyses were carried out with a beam spot size of approximately $1 \mathrm{~mm}^{2}$ under normal incidence. The backscattered $\mathrm{He}^{+}$particles were measured with a surface barrier detector (ORTEC) at a scattering angle of $170^{\circ}$ at a distance of about $12 \mathrm{~cm}$ from the target. The measured energy resolution of the detector is $13 \mathrm{keV}$ (FWHM), resulting in a depth resolution of approximately $40 \mathrm{~mm}$ in the photoresist. The ion beam current was varied from 25 to $150 \mathrm{nA}$ and was measured, using an electrometer (Keithley Instruments), directly from the target, which was kept at $+100 \mathrm{~V}$ to surpress secondary ions.

ERD experiments were carried out at a scattering angle of $27.5^{\circ}$ with the detector at a distance of $19 \mathrm{~cm}$ from the target. The angle chosen between the incoming beam and the sample normal was $75^{\circ}$ using the 3-axis sample manipulator (Maclean). An 8.9-4m Mylar foil in front of the detector was used to absorb the forwardly scattered helium ions. An additional diaphragm of $3.5 \times 5.6 \mathrm{~mm}^{2}$ in front of the detector was used to control energy variations caused by differences in scattering angle over the detector.

Count rates of hydrogen atoms were measured by installing a singie channel analyzer (SCA) and count rate meter connected to the research amplifier. The energy window of the SCA was chosen such that all H counts from the polystyrene layer were detected.

The samples to be analyzed were placed directly into the high vacuum chamber $\left(10^{-4} \mathrm{~Pa}\right)$ without any special precautions to prevent outgassing of the polymers under megaelectron volt irradiation.

\section{SIMS experiments}

SIMS measurements were performed on a CAMECA IMS3F instrument using $\left(\mathrm{O}_{2}^{+}\right)$primary ions at an energy of $5.5 \mathrm{keV}$. The primary beam was rastered across an area of $250 \times 250 \mu \mathrm{m}^{2}$ and positive secondary ions were detected from the center of the sputtered area (diameter $60 \mu \mathrm{m}$ ). Depth profiles of ${ }^{30} \mathrm{Si}^{-t}$ and ${ }^{12} \mathrm{C}^{+}$were determined.

Quantitative evaluation of the Si content of the silylated resist was not performed because of charging and the lack of suitable standards. Depth scale calibration was performed by measuring the depth of the sputtered crater using a stylus type profilometer (Tencor Alphastep). The sputtering rate for silylated resist was found to be higher than for nonsilylated material (a factor of 1.5 was found for a resist layer con. taining 9 at. \% silicon).

\section{RESULTS ANO DISCUSSION A. Sllicon protiles in resist layers}

RBS experiments were carried out on silylated resist layers. Figure 2 shows two RBS spectra. The upper spectrum shows a resist layer just after the treatment with HMDS. A peak corresponding to the incorporated silicon is clearly distinguishable. In the spectrum this peak is superimposed on a sulfur background caused by the photoactive compound (sulfonic acid ester) that is present over the entire photoresist layer.

The lower part of Fig. 2 shows the spectrum after treatment with an oxygen plasma. A small peak corresponding to a thin layer of silicon dioxide can be distinguished on top of the signal of the incorporated Si. Both spectra clearly show that only a finite part of the resist layer is converted. The Si is only present in the rop part of the polymer layer.

In order to study the infuence of degradation, a set of consecutive RBS spectra were measured at one particular spot of the silylated resist layer. The spectra obtained were 


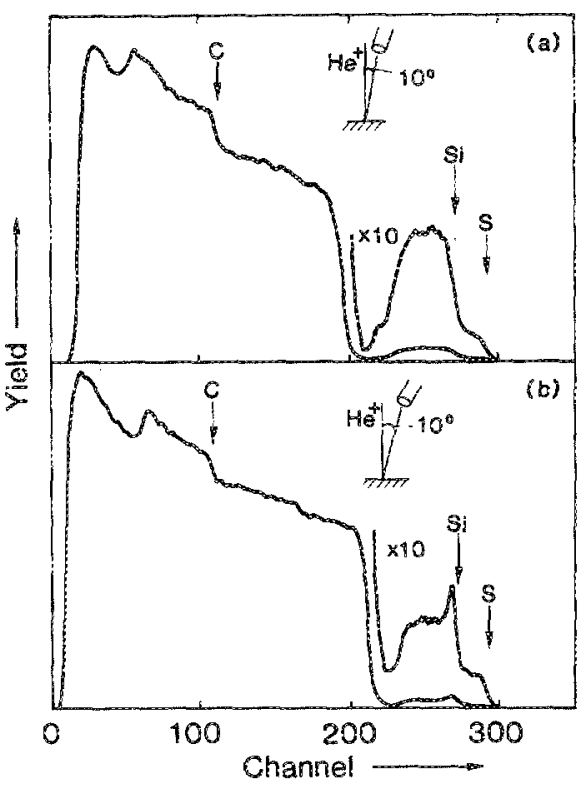

FIG. 2. RBS spectra of a silylated photoresist layer (a) before and (b) after oxygen plasma etching.

very similar to the spectrum shown in Fig. 2(a). Degradation of the polymer with dose was clearly observed in the form of a shift of the Si signal edge of the underlying substrate to higher energies. With a dose of $3 \times 10^{i 6}$ ions $/ \mathrm{cm}^{2}$, a shift of $\sim 30 \mathrm{keV}$ was measured, indicating a loss of material from the photoresist layer. Degradation was also noticed by visual inspection of the wafer. A small brownish square indicated the position of the beam at the sample.

In order to calculate the number of $\mathrm{Si}$ atoms $/ \mathrm{cm}^{2}$ as a function of the He ion dose, a linear fit was drawn through the underlying sulfur signal in each spectrum and the residual integral was converted into the number of incorporated Si atoms $/ \mathrm{cm}^{2}$. In Fig. 3 this number is plotted versus the integrated $\mathrm{He}^{+}$dose on the sample.

Within measuring accuracy the Si integral is shown to be constant. Apparently only small, volatile, components are released during the He ton bombardment and silicon is preserved. Further examination of the spectra also showed that the rectangular shape of the Si profile had not altered. The expected increase in the atomic concentration of $\mathrm{Si}$ in the resist layer was apparently not enough to increase the $\mathrm{Si}$ signal height within measuring accuracy. This effect can be understood, since the height of the Si signal is only determined by the value of the stopping power elev/atoms/ $\mathrm{cm}^{2}$ ). The contribution of the hydrogen present in the film to $e$ is small, therefore, if it is predominantly hydrogen atoms which leave the resist layer, there will be hardly any change in $e$, whereas the atomic composition does change.

An independent check on the infuence of the $\mathrm{He}^{+}$beam on the shape of the Si profile was provided by SIMS experiments. Enitial measurements on a virgin sample generally resulted in profles being heavily distorted due to charging: low signal intensities and a ${ }^{12} \mathrm{C}^{+}$matrix reference signal which was not constant as a function of spattered depth. Attempts to reduce charging effects using electron flooding

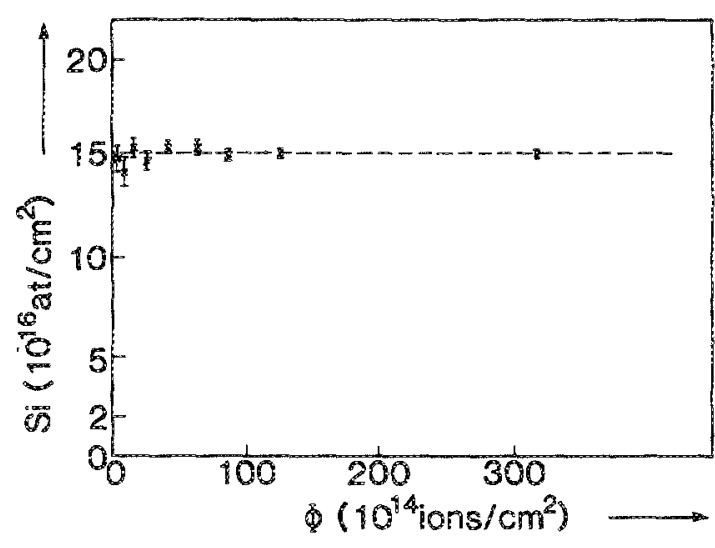

FTC. 3. The number of Si atoms incorporated as a function of the incident He ion dose in an RBS measurement.

were only partiry successful. However, after several measurements at different points on the sample (without removing it from the instrument) charging effects were found to be absent in the next measurement. Systematics with respect to the occurrence of this situation could not be established. Possibly secondary electrons, generated at the extraction electrode and accelerated towards the sample, play a role; as noted before ${ }^{6}$ energetic, deeply penetrating particles may render polymer materials conductive. Detailed information on the occurrence of such processes in the mass spectrometer is not available, thereby preventing a more systematic investigation. All SIMS profles were obtained from such possibiy conducting spots, since disturbing effects caused by charging are absent in these cases.

Several wafers with different amounts of silicon incorporated have been measured with RBS producing a spot on the resist layer. SIMS measurements were then carried out in these spots and next to them. In this case too the conductivity of the sample (induced by the $2 \mathrm{MeV} \mathrm{He}^{+}$bombardment) was sufficiently high to prevent charging. As identical silicon profiles were obtained from points both with and without prior RBS measurement it is suggested that bombardment with $\mathrm{He}^{+}$ions in the megaelectron volt energy range is a valuable method for preventing charging problems in subsequent SMS-depth profling of inorganic components in resists or other polymer materials.

In order to convert the energy scale in the RBS spectrum to a depth scale in nanometers, the composition and density of the silylated resist layer must be known. The atomic composition of the exposed unreacted resist was determined by chemical analysis. Upon silylation Si( $\left.\mathrm{CH}_{3}\right)_{3}$ groups are incorporated and swelling of the layer occurs. The atomic composition and density of the top layer could be determined by measuring the layer thickness and the increase in mass upon silylation.

Although the layer composition changes with the He ion dose, the energy to depth conversion factor ( $\mathrm{eV} / \mathrm{nm}$ ) was calculated using Bragg's rule and the original composition of the nondegraded layer. Figure 4 shows the depth profle obtained in this way compared with the profile obtained using SIMS. The agreement between both depth sales 


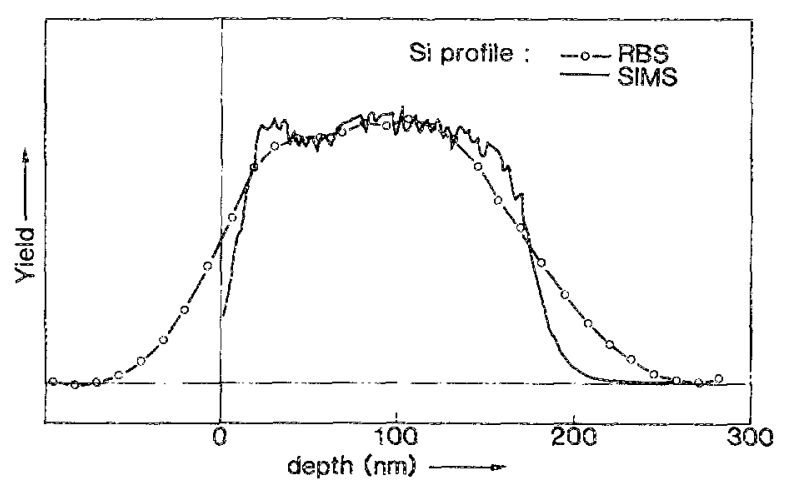

FIG. 4. Si-depth profles obtained with RBS and SIMS. The vertical scale for the SIMS profile has been normalized on the RIS yield.

and profiles demonstrates the applicability of RBS in this system. Also Fig. 4 demonstrates the differences in depth resolution of RBS and SIMS.

With the results presented above in mind, an overall qualitative picture of the degradation process can be envisaged. At energies sightly below $2 \mathrm{MeV}$ the nuclear stopping power of $\mathrm{He}^{-}$ions is negligible with respect to the electronic stopping. The vast majority of the incident $\mathrm{He}^{+}$ions lose $\sim 180 \mathrm{keV}$ during their passage through the resist layer of approximately $10^{19}$ atoms $/ \mathrm{cm}^{2}$. The electronic stopping power only changes by $\sim 3 \%$ between 1.8 and $2 \mathrm{MeV}$ and the $\mathrm{He}^{+}$ions therefore deposit electronic energy almost uniformly with depth. In principle, the degradation occurs homogeneously with depth and if the escape of molecules from deeper layers is assumed, ${ }^{7}$ Si profiles will not be altered. In order to lose small molecules from the polymer, electronic energy first has to be converted into nuclear motion.

Jolnson and Brown ${ }^{9}$ reviewed electronic mechanisms for sputtering from condensed gas solids. Although, in principle, the degradation of polymers is a different subject, one of their mechanisms may very well be applicable in this case. ${ }^{10}$

The passage of an ion through the resist layer temporariy causes a positive charged track surrounded by a negative shell of displaced electrons. Large electric fields in the arder of $10^{7} \mathrm{~V} / \mathrm{cm}$ which are needed to accelerate nuclei from their equilibrium position on a molecular scale can exist long enough to cause dissociation or electronic excitation. This so-called "Coulomb explosion" mechanism is favored in polymers because of the absence of delocalized electrons as in a typical semiconductor, which can quickly $\left(<10^{-14} \mathrm{~s}\right)$ neutralize the transient fields. Since the bond electrons in the polymer have typical poiarization frequencies in the order of $10^{13} \mathrm{~Hz}$ this leaves enough time $\left(10^{-13} \mathrm{~s}\right)$ for bond rupture or excitation. Reactive atoms or radicals formed by this mechanism can then recombine and form small volatile stable molecules which can diffuse out of the polymer layer on time scales several orders of magnitude larger (seconds). This constrasts with semiconductors, in which only defects can be created. As already mentioned in the introduction, the diffusion of these small species has been observed experimentally. The constant number of $\mathrm{Si}$ atoms $/ \mathrm{cm}^{2}$ with incident $\mathrm{He}$ ion dose implies the formation of nonvolatile Sicontaining compounds. An FT-IR measurement in an RBS spot gives a much lower intensity of the Si-O-aryl stretching vibration than in the original sample. This indicates that $\mathrm{Si}$ must be present in a form different from the original silylether compound. Most likely, nonvolatile Si compounds (oxides or carbides) freeze the original profile in the remaining processed hydrocarbons. The ultimate state of the irradiated polymer is perhaps best described by large conjugated molecules, probably mostly in the form of polyaromatic hydrocarbons. ${ }^{6}$ The conjugated $\pi$ electrons are responsible for the decreased resistivity of the polymer layer which explains the success of the SIMS experiments.

\section{B. Degradation of polystyrene}

The areal densities of $\mathrm{C}, \mathrm{O}$, and $\mathrm{S}$ which can be derived from the spectra of the UCB-Plasmask photoresist do not allow a quantitative description for the degradation process. The wider application of RBS in polymers containing aromatic rings, as novolak, however, inspired us to attempt to describe the degradation process for the chemically simple model system of a 560 -nm-thin layer of polystyrene $\left(\mathrm{C}_{n} \mathrm{H}_{n}\right)$ on $\mathrm{Si}$.

The decrease of the number of hydrogen atoms $/ \mathrm{cm}^{2}$ with incident dose was measured directly by monitoring the count rate in a $2 \mathrm{MeV}^{4} \mathrm{He}^{+} \mathrm{ERD}$ experiment. The decrease of the carbon content in the layer was then derived from the position of the Si substrate signal edge.

Figure 5 shows the normalized decrease of the hydrogen count rate with dose. A remarkable feature is the initial fast decrease, while for doses larger than $10^{16}$ ions $/ \mathrm{cm}^{2}$ a quasiasymptotic value is approached, possibly corresponding to the hydrogen content of a fairly stable end product when long irradiation times are used.

The measured curve can be described starting from the following equation:

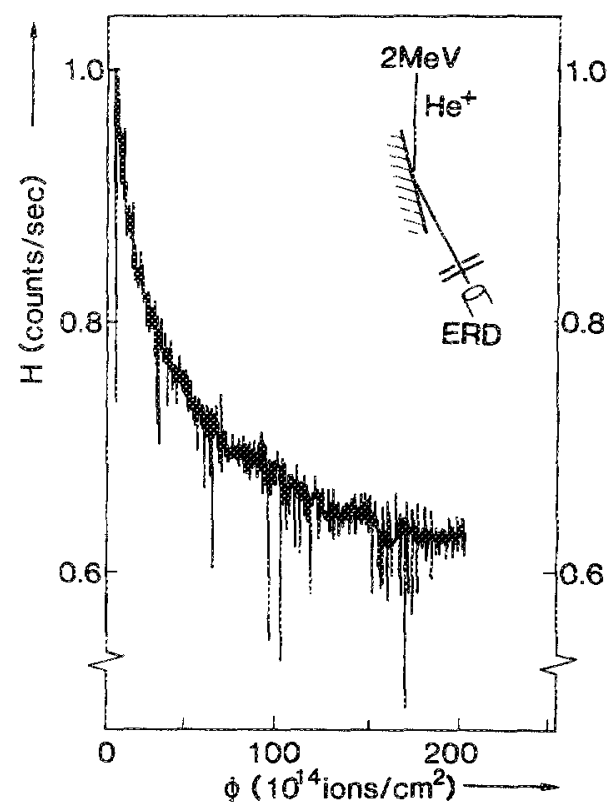

FIG. 5. Normalized hydrogen counts per second vs the incident dose for an ERD measurenent on a 560-nm polystyrene layer. 


$$
\frac{d \mathrm{H}}{d \phi}=-\sigma_{\mathrm{H}}\left(\mathrm{H}-a_{\mathrm{H}} \mathrm{H}_{0}\right)
$$

$H$ represents the dose-dependent number of hydrogen atoms $/ \mathrm{cm}^{2}$ in the layer, while $\mathrm{H}_{0}$ is the value of $\mathrm{H}$ for zero dose $(\phi), \sigma_{H}$ represents a dose-independent degradation cross section and $a_{\mathrm{y}}$ is the fraction of the hydrogen atoms originally present, which remains in the end product. The use of a dose-independent degradation cross section is based on the stopping power of $2 \mathrm{MeV} \mathrm{He}{ }^{+}$in polystyrene which is $\sim 16.5 \mathrm{eV} / 10^{15}$ atoms $/ \mathrm{cm}^{2}$. The energy deposited locally by the passage of a He ion through a monolayer is therefore considerably larger than the typical energy $(\sim 3 \mathrm{eV})$ required to break a covalent $\mathrm{C}-\mathrm{H}$ bond. Structural changes in the polymer do not raise this bond energy significantly and a dose-dependent degradation cross section is not expected.

Integration of ( 1 ) gives

$$
\ln \left(\frac{\mathrm{H}}{\mathrm{H}_{\mathrm{O}}}-a_{\mathrm{H}}\right)=-\sigma_{\mathrm{H}} \phi+\ln \left(1-a_{\mathrm{H}}\right) \text {. }
$$

Thus, the value of $\sigma_{\mathrm{H}}$ can be determined by adopting $a_{\mathrm{H}}$ such that the correlation coefficient for the linear plot of $\ln \left[\left(\mathrm{H} / \mathrm{H}_{0}\right)-a_{\mathrm{H}}\right]$ vs $\phi$ is optimized. The resulting value of $a_{H}$ from the intercept can then serve as a test for this procedure. A correlation coefficient of 0.99963 was found for $a_{\mathrm{H}}=0.60$ while the corresponding value of $a_{\mathrm{k}}$ from the intercept was 0.63 . The degradation cross section $\left(\sigma_{C}\right)$ was found to be $5.5 \times 10^{-16} \mathrm{~cm}^{-2}$ (Fig. 6).

The dependence of $\sigma_{\xi 1}$ and $a_{\mathrm{H}}$ on incident beam current denstiy was investigated. A variation from 25 to $150 \mathrm{nA} / \mathrm{cm}^{2}$ resulted in a change in cross section from 5.5 to $5.0 \times 10^{16}$ atoms $/ \mathrm{cm}^{2}$ and a change in $a_{\mathrm{H}}$ from 0.60 to 0.64 . These results support the idea that thermal effects play only a minor role. When a heat conductivity of polystyrene of $2.5 \times 10^{-3} \mathrm{~W} / \mathrm{cm}{ }^{\circ} \mathrm{C}$ and a deposited energy of $\sim 200 \mathrm{keV}$ in the polymer is assumed, a temperature rise of approximately $15-80^{\circ} \mathrm{C}$ is expected in the beam current interval used. This temperature rise is below the temperature at which thermal degradation is expected.

The quantification of the loss of carbon from the layer is extracted from a series of consecutive RBS spectra. The shift of the signal edge of the Si substrate with dose is shown in Fig. 7.

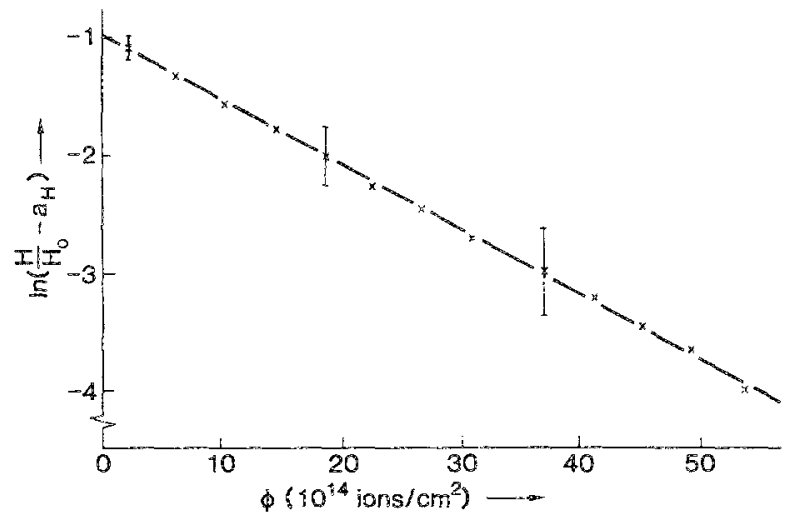

FIG. 6. A plot of in $\left[\left(H / \mathrm{H}_{0}\right) \cdots a_{\mathrm{H}}\right]$ vs $\phi$ gives a straight line; the intercept gives $a_{\mathrm{H}}=0.62+0.02$ and $\sigma_{\mathrm{H}}$ follows from the slope, $\sigma_{53}=(5.5$ $+0.3) \times 10^{-16} \mathrm{~cm}^{2}$.

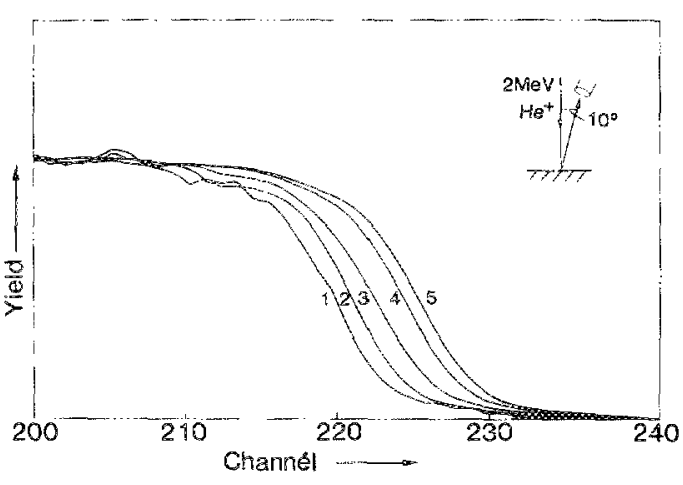

FIC 3.7 . Degradation of $560-12 m$ polystyrenc on a Si wafer: the edge of the Si substrate shifts to a higher channel number as a funcion of dose, $3(1)$, $18(2), 61(3), 151(4)$, and $304 \times 10^{14} \mathrm{ions} / \mathrm{cm}^{2}(5)$.

Complicating factors in the interpretation of this effect are both the continuously changing composition of the layer during the measurement and the fact that the shift is caused by both $H$ and $C$. The shift of the Si substrate can be described by

$$
\Delta E=\int_{0}^{\phi}[C(\phi)+H(\phi)] \epsilon_{\mathrm{Si}}^{C(\phi) H(\phi)} d \phi / \int_{0}^{\phi} d \phi .
$$

$\Delta E$ represents the energy shift (at half-height position) of the signal edge of the substrate with respect to the Si surface energy and $\epsilon_{\mathrm{Si}}^{\mathrm{C}(\phi) \mathrm{H}(\phi)}$ is the electronic stopping power in a material $\mathrm{C}(\phi) \mathrm{H}(\phi)$ including a collision against a Si atom in the substrate. Using Bragg's rule the contribution of carbon and hydrogen to the shift can be separated:

$$
\phi \Delta E=\int_{0}^{\phi}\left[\mathrm{C}(\phi) \epsilon_{\mathrm{Si}}^{\mathrm{c}}+\mathrm{H}(\phi) \epsilon_{\mathrm{Si}}^{\mathrm{H}}\right] d \phi .
$$

The second term of the integral can be evaluated with the expression used in the ERD experiments. What remains is the integrated dose dependence of the number of carbon atoms $/ \mathrm{cm}^{2}$. Further evaluation of the data in terms of a degradation cross section $\left(\sigma_{C}\right)$ has to be based on an explicitly assumed functional dependence of $\mathrm{C}$ vs $\phi$.

In the following we assumed

$$
\mathrm{C}(\phi)=\mathrm{C}_{0}\left[\left(1-a_{\mathrm{C}}\right) \exp \left(-\sigma_{\mathrm{C}} \phi\right)+a_{C}\right] \text {, }
$$

in which $\sigma_{\mathrm{c}}$ is the degradation cross section for carbon and $a_{C}$ the fraction of the originally present carbon $\mathbb{C}_{0}$ which results in the end product. This assumption is based on the still relatively low binding energies of $\mathrm{C}$ in the polymer when compared with energy deposited by the passage of a He ion. Insertion of (2) and (5a) into (4) and integration yields an analytical expression in which the absolute values of $\mathrm{C}_{0}$ and $\mathrm{H}_{0}$ are required in order to calculate $\sigma_{\mathrm{C}}$ and $a_{\mathrm{C}}$. This disadvantage can be discarded on evaluating the relative shift in energy $\Delta E / \Delta E_{0}$ in which

$$
\Delta E_{0}=H_{0} \epsilon_{\mathrm{Si}}^{\mathrm{H}}+\mathrm{C}_{0} \epsilon_{\mathrm{Si}}^{\mathrm{C}},
$$

represents the shift if no degradation takes place.

The value of $\Delta E_{0}$ can be determined from the experiment by extrapolating $\Delta E$ measurements to $\phi=0$. The total shift can then be regarded as having two contributions, i.e., one for $\mathrm{H}$ and one for $\mathrm{C}$ : 


$$
\begin{aligned}
\frac{\Delta E}{\Delta E_{0}}-\left(\frac{\Delta E}{\Delta E_{0}}\right)_{\mathrm{H}}= & \frac{\left(1-a_{\mathrm{C}}\right)}{\sigma_{\mathrm{C}} \phi}\left[1-\exp \left(-\sigma_{\mathrm{C}} \phi\right)\right] \\
& +\left(1-\epsilon_{\mathrm{J}}\right) a_{\mathrm{C}}
\end{aligned}
$$

in which

$$
\epsilon_{f}=\epsilon_{\mathrm{Si}}^{\mathrm{H}} /\left(\epsilon_{\mathrm{Si}}^{\mathrm{C}}+\epsilon_{\mathrm{Si}}^{\mathrm{H}}\right)=0.187 .
$$

This equation can be rewritten in the form

$$
\ln \left[\left(1 / \sigma_{C}\right)-B\left(a_{C}\right)\right]=\ln \left(1 / \sigma_{C}\right)-\sigma_{c} \phi
$$

$B$ contains only measurable quantities and, in addition, $a_{\mathrm{C}}$. The relation was investigated by selecting values of $a_{C}$ and consecutively adopting $\sigma_{\mathrm{C}}$ until an optimal correlation coefficient was found. Unfortunately, no $a_{C}$ with an optimal correlation coefficient was found in this procedure. Values of $a_{\mathrm{C}}$ varying between 0.6 and 0.9 all yield correlation coefficients in excess of 0.999 . The corresponding degradation cross section, however, varies only between 1 and $4 \times 10^{-17} \mathrm{~cm}^{-2}$, which delimits the order of magnitude for $\sigma_{\mathrm{C}}$ in the $10^{-17}$ $\mathrm{cm}^{-2}$ range.

Comparison with the degradation cross section of hydrogen $\left(\sigma_{\mathrm{H}}\right)$ shows that the assumed asymptotic value of $a_{\mathrm{C}}$ is only reached with an one order of magnitude larger integrated He ion dose. In this respect the poor accuracy in the procedure described above could be expected since the He ion dose adopted in the experiments is only limited. This is also supported by values obtained for $\Delta E / \Delta E_{0}$ for doses $<10^{17}$ ions $/ \mathrm{cm}^{2}$ which all yield 0.813 , corresponding to the vaiue of $\left(1-e_{f}\right)$. For $\sigma_{\mathrm{C}}<1,(6 a)$ approaches $\left(1-e_{f}\right)$.

The experiments described in the section on Si profiles in resist layers have been measured with $\mathrm{He}$ ion doses of $\sim 50-100 \times 10^{14}$ ions $/ \mathrm{cm}^{2}$. If the model above is applicable, the decrease in $\mathrm{C}$ content of the layer is only minor in this dose range, which supports that the areal densities calculated from the RBS spectra are still reliable.

\section{CONCLUSIONS}

Depth profiles of Si in the photoresists have been obtained with RBS. Despite the noticeable degradation of the photoresist upon megaelectron volt irradiation, no signin̂* cant alteration of the shape of the Si profile was found up to incident doses of $3 \times 10^{16}$ ions $/ \mathrm{cm}^{2}$. Si profiles obtained by
SIMS both in and next to the RBS-irradiated area do not show significant differences.

The total areal density of $\mathrm{Si}$ is also preserved in the dose range up to $3 \times 10^{16}$ ions $/ \mathrm{cm}^{2}$. Apparently electronic excitation induces a degradation process homogeneous with depth, in which nonvolatile Si compounds freeze out the original profile.

ERD experiments monitoring the decrease of hydrogen from a polystyrene layer allow a degradation model with only one degradation cross section which is dose independent. No significant beam current dependence of this cross section was found in the range $25-150 \mathrm{nA}$. This supports the proposed mechanism of degradation via excitation of covalent bonds.

\section{ACKNOWLEDGMENTS}

We would like to thank A. M. L. Theunissen for his assistance with the RBS measurements, Dr.P.R. Boudewijn for carrying out the SIMS experiments, Dr. R. J. Visser for many useful discussions and UCB-Electronics for providing the Plasmask photoresist samples.

'E. D. Wolf, G. N. Taylor, T. Venkatesan, and R. T. Kretsch, J. Electrochem. Soc. 131, 1664 (1984).

${ }^{2} \mathrm{~F}$. Coopmans, $\mathbb{B}$. Roland, and R. Lombaerts, Proceedings of the Microcircuit Engineering Conference, Interlaken, 291 (1986).

${ }^{2}$ R. J. Visser, J. P. W. Schellekens, M. E. Reuhman-Huisken, and L. J. van IJzendoorn, Proc. SPIE 771, 111 (1987).

${ }^{4}$ P. J. Nills, C. J. Palmstrdm, and E. J. Kramer, J. Mater. Sci. 21, 1479 (1986).

${ }^{5}$ P. F. Greene and B. L. Doyle, Nucl. Instrum. Methods B 18, 64 (1986). ${ }^{6}$ T. Venkatesan, S. R. Forrest, M. L. Kaplan, C. A. Murray, P. H. Schmidt, and B. J. Wilkens, J. Appl. Phys. 54, 3150 (1983).

7T. Venkatesan, D. Edelson, and W. L. Brown, Appl. Phys. Lett. 43, 364 (1983).

"L. Calcagno and G. Foti, Appl. Phys. Lett. 47, 363 (1985).

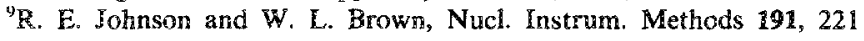
(1981).

${ }^{13}$ T. Venkatesan, L. Caicagno, B. S. Elman, and G. Foti, in Ion Beam Modification Of Insuiators, edited by P. Mazzoldi and G. W. Arnold (Elsevier, New York, 1987). 